\title{
Erratum to: Prediction model and prognostic index to estimate clinically relevant pelvic organ prolapse in a general female population
}

\author{
Marijke Slieker-ten Hove • Annelies Pool-Goudzwaard • \\ Marinus Eijkemans • Regine Steegers-Theunissen • \\ Curt Burger • Mark Vierhout
}

Published online: 8 January 2010

(C) The International Urogynecological Association 2009

\section{Erratum to: Int Urogynecol J \\ DOI 10.1007/s00192-009-0903-0}

Incorrect data were given for the prevalence of clinically relevant POP. The correct overall presence of clinically relevant POP ( $\geq$ stage $2 \mathrm{~B}$ ) was $17.5 \%(n=114)$. Within this group, $30.7 \%(n=35)$ were symptomatic.

Furthermore, Table 4 was presented without the accompanying prognostic curve.

The authors sincerely regret these errors.

The online version of the original article can be found at http://dx.doi. org/10.1007/s00192-009-0903-0.

M. Slieker-ten Hove $\cdot$ R. Steegers-Theunissen Department of Obstetrics and Gynaecology, Erasmus MC, University Medical Centre,

Rotterdam, The Netherlands

\author{
A. Pool-Goudzwaard \\ Department of Neuroscience, Erasmus MC, \\ University Medical Centre, \\ Rotterdam, The Netherlands
}

\section{Eijkemans}

Department of Public Health, Erasmus MC,

University Medical Centre,

Rotterdam, The Netherlands

\section{R. Steegers-Theunissen}

Department of Epidemiology,

Erasmus University Medical Centre,

Rotterdam, The Netherlands
R. Steegers-Theunissen

Department Paediatrics/Paediatric Cardiology, Erasmus MC,

University Medical Centre,

Rotterdam, The Netherlands

R. Steegers-Theunissen

Department Clinical Genetics, Erasmus MC,

University Medical Centre,

Rotterdam, The Netherlands

C. Burger

Department of Obstetrics and Gynaecology/Division

of Gynaecologic Oncology, Erasmus MC,

University Medical Centre,

Rotterdam, The Netherlands

M. Vierhout

Department of Obstetrics and Gynaecology,

Radboud University Nijmegen Medical Centre,

Nijmegen, The Netherlands

M. Slieker-ten Hove $(\square)$

Softwareweg 5,

3821 BN Amersfoort, The Netherlands

e-mail: m.slieker@somt.nl 
Table 4 The Slieker POP score chart and the prognostic index to read the sum score

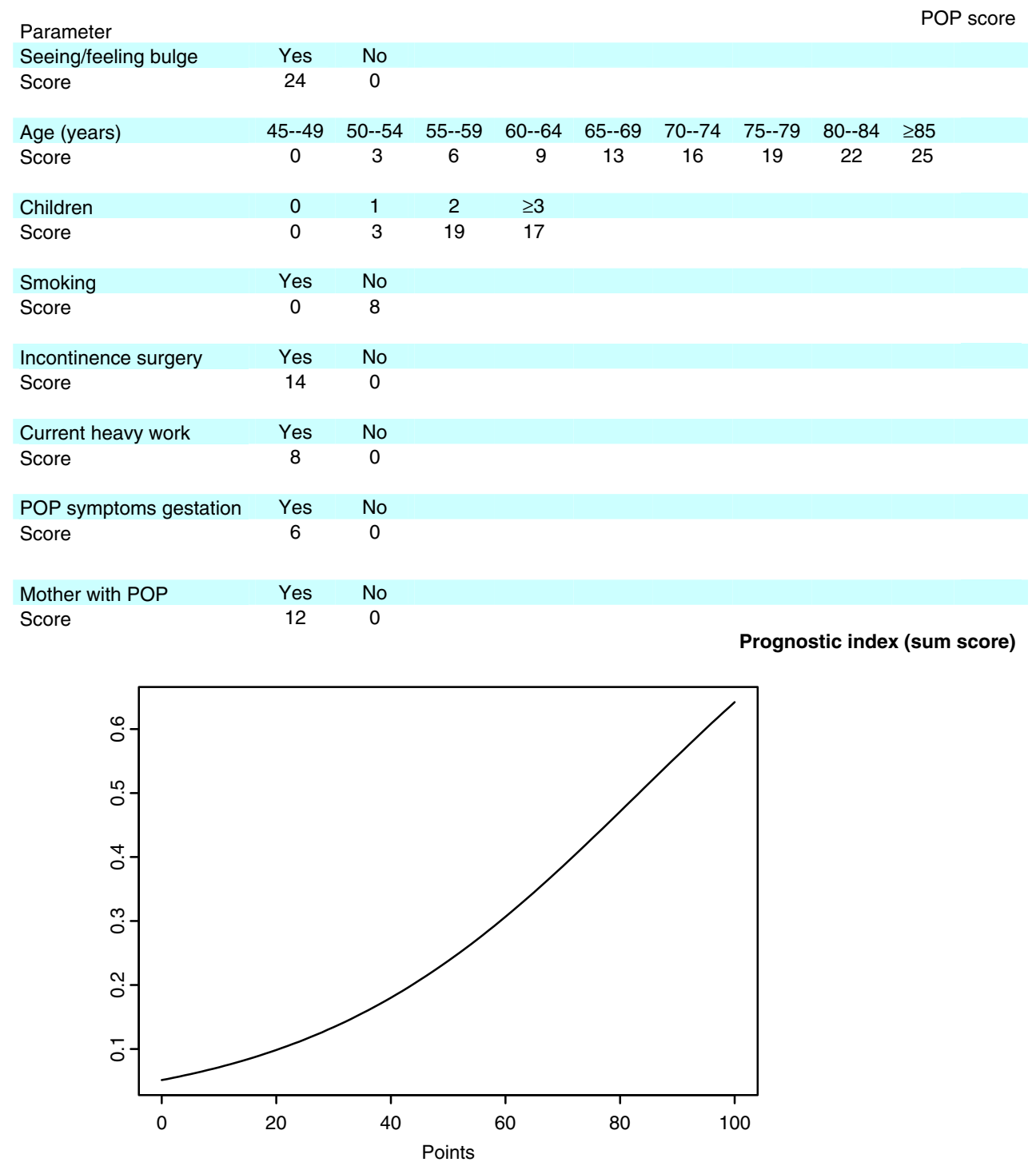

